\title{
Utilização de Soja Integral Tostada na Dieta de Vacas em Lactação, em Pastagem de Coastcross (Cynodon dactylon, L. Pers.)
}

\author{
Duarte Vilela1, Leovegildo Lopes de Matos ${ }^{1}$, Maurilio José Alvim¹, João Batista Matiolli²
}

\begin{abstract}
RESUMO - O objetivo deste trabalho foi avaliar o efeito da inclusão da soja integral tostada (SIT) no concentrado suplementar de vacas da raça Holandesa em pastagem de coastcross. Foram utilizadas 12 vacas no início da lactação, divididas em dois grupos: A) as que receberam concentrado padrão (testemunha), contendo farelo de soja (23,5\% PB e $80 \%$ NDT) e B) as que receberam concentrado com SIT (19,5\% PB, 86\% NDT). Nos dois tratamentos, foram fornecidos, diariamente, $9 \mathrm{~kg}$ de concentrado por vaca. Usou-se cerca eletrificada para auxiliar no manejo da pastagem, que se baseou em pastejo rotativo, com um dia de ocupação dos piquetes, por 25 dias de descanso. O experimento teve duração de 100 dias, durante o verão, quando foram aplicados na pastagem 140,32 e $112 \mathrm{~kg} / \mathrm{ha}$ de N, $\mathrm{P}_{2} \mathrm{O}_{5}$ e $\mathrm{K}_{2} \mathrm{O}$, respectivamente, divididos em quatro aplicações. A inclusão de SIT aumentou a produção de leite, a produção de leite corrigido para 3,5\% de gordura, que foram, em média: 22,2 e 23,6;19,8 e 19,7 kg/vaca/dia, para os tratamentos SIT e testemunha, respectivamente. Os teores de gordura no leite foram de 4,16 e 3,49\% nos tratamentos em que os animais receberam concentrado com SIT e concentrado padrão, respectivamente. As vacas que receberam concentrado com SIT mostraram produção superior ao grupo testemunha, atingindo $145,4 \mathrm{~kg} / \mathrm{ha} / \mathrm{dia}$ de leite. Nos dois tratamentos, as vacas ganharam peso.
\end{abstract}

Palavras-chave: energia, produção de leite, suplementação de pastagem, taxa de lotação

\section{Utilization of Roasted Whole Soybean for Lactating Cows Feeding, Grazing Coastcross-1 (Cynodon dactylon, L Pers.)}

\begin{abstract}
The purpose of this study was to evaluate the effect of the inclusion of roasted whole soybean (RWS) in the concentrate composition to be employed to supplement feeding of Holstein cows on coastcross-1 pasture. Twelve early-lactating cows were utilized, divided into two groups as follows: A) the ones fed standard concentrate (control) containing soybean meal (23.5\% CP and $80 \% \mathrm{TDN})$ and $\mathrm{B}$ ) the ones fed RWS-enriched concentrate (19.5\% CP and $86 \% \mathrm{TDN})$. In two treatments, daily feeding was of $9 \mathrm{~kg} / \mathrm{cow}$ of concentrate. An electric fence was utilized for helping pasture management, which was based on rotational grazing, with one day of paddock occupation and a resting period of 25 days. The experiment lasted 100 days, during the summer, when the pasture was fertilized with 140,32, and $112 \mathrm{~kg}$ /ha of, respectively, $\mathrm{N}, \mathrm{P}_{2} \mathrm{O}_{5}$ and $\mathrm{K}_{2} \mathrm{O}$, divided into four applications. The inclusion of RWS caused an increase in milk production and in fat-corrected (to 3.5\%) milk production, which were, in average: 22.2 and 23.6 and 19.8 and $19.7 \mathrm{~kg} / \mathrm{cow} /$ day, for RWS-enriched and control treatments, respectively. The milk fat levels were 4.16 and $3.49 \%$ in the plots, where animals were fed, respectively, RWS-enriched and standard concentrate. The cows fed RWS-enriched concentrate exhibited superior milk production than the ones fed standard concentrate, reaching $145.4 \mathrm{~kg}$ milk/ha/day. In both treatments the cows showed weight gains.
\end{abstract}

Key Words: energy, milk production, pasture supplementation, stocking rate

\section{Introdução}

Sob o ponto-de-vista da alimentação do rebanho, pasto é o mais barato de todos os alimentos (Vilela et al., 1996). Diversos trabalhos têm mostrado que os sistemas de produção de leite baseados em pastagens bem manejadas necessitam de menores dispêndios com suplementação alimentar, possibilitando maiores retornos líquidos (Bryant, 1993). A intensificação da produção de leite em pastagens tropicais resulta, principalmente, das elevadas lotações, que algumas gramíneas tropicais podem suportar (Alvim et al., 1997; 1999). Potencialmente, as pastagens tropicais podem suprir nutrientes para manter produções diárias de $12 \mathrm{~kg} / \mathrm{vaca}$ de leite, sem o uso de alimentação suplementar (Stobbs, 1976). Cowan(1995) afirma que o limite de produção de leite de vacas em pastagens tropicais, sem recorrer ao uso de concentrados, não excede a $4.500 \mathrm{~kg} /$ lactação, tendo a qualidade e disponibilidade do pasto como determinantes desse limite.

Dentre as gramíneas tropicais, as do gênero Cynodon, entre as quais o coastcross, apresentam

\footnotetext{
${ }^{1}$ Pesquisador da Embrapa - Centro Nacional de Pesquisa de Gado de Leite (CNPGL), Rua Eugênio do Nascimento, 610, Dom Bosco, CEP 36038-330 Juiz de Fora, MG. E-mail: vilela@cnpgl.embrapa.br. Bolsista do CNPq.

${ }_{2}$ Assistente de Pesquisa da Embrapa - CNPGL
} 
características forrageiras desejáveis para serem utilizadas sob pastejo, como elevada produção e distribuição anual de matéria seca, boa relação folha/ colmo e alto valor nutritivo (Herrera, 1983; Alvim et al. 1998). Vacas com potencial genético para produzir 6 a 7 mil quilogramas por lactação, mantidas em pastagem de coastcross, mostram incremento marginal de $1 \mathrm{~kg}$ de leite em resposta à suplementação com $1 \mathrm{~kg}$ de concentrado (Vilela et al. 1996). Pastagens de coastcross devidamente adubadas, com utilização de irrigações estratégicas e manejadas em pastejo rotativo, propiciam de 13 a $14 \mathrm{~kg} / \mathrm{vaca} /$ dia de leite, após abatida a contribuição nutricional advinda da alimentação suplementar com concentrados (Alvim et al., 1997; 1999; Vilela et al., 1996).

Vilela et al. (1996) avaliaram vacas puras holandesas mantidas em confinamento ou em pastagem de coastcross recebendo três quilogramas de concentrado/vaca/dia, obtendo produções de 20,6 e 16,6 kg/ $\mathrm{vaca} /$ dia de leite, respectivamente, com uma taxa de lotação média de 5,8 vacas/ha para a pastagem de coastcross. Concluíram que, embora a receita proveniente do leite comercializado no sistema a pasto tenha sido inferior a do sistema confinado, a margem bruta foi $32 \%$ superior, indicando que o pastejo em coastcross se constitui em alternativa viável para a intensificação da pecuária leiteira na Região Sudeste do Brasil. Resultados bioeconômicos semelhantes foram obtidos por Fontaneli (1999), com pastagem de Tifton-85, na Flórida.

A ingestão de energia é o fator limitante da produção de leite de vacas mantidas em pastagens tropicais bem manejadas (Davison et al., 1982; Reeves et al., 1996). Vacas no início da lactação não são capazes de consumir energia suficiente para sustentar a crescente produção de leite, levando-as à mobilização de reservas corporais (NRC, 2001). Por outro lado, o fornecimento de quantidades muito elevadas de concentrados ricos em carboidratos não estruturais, pode levar a queda no teor de gordura do leite, acidose, depressão na degradabilidade da fibra e redução no consumo de matéria seca (Van Soest, 1994). A estratégia de se fornecer alimentação suplementar com maior densidade energética pode ser conseguida com a inclusão de lipídeos insolúveis no rúmen, de forma a não comprometer a fermentação ruminal (Nocek, 1995, Van Soest, 1994).

A proteína do pasto fica sujeita à rápida e intensa fermentação ruminal, com conseqüente aumento na concentração de $\mathrm{N}$ amoniacal e perdas expressivas de N no rúmen (Berzaghi et al., 1996; Van Soest, 1994). Os animais a pasto apresentam o fluxo de $\mathrm{N}$ para o intestino delgado basicamente de origem microbiana, indicando grande atividade de síntese microbiana ruminal, o que sugere potencial para resposta produtiva à suplementação com carboidratos não estruturais e com fontes de proteína não degradável no rúmen (Berzagui et al., 1996). Entretanto, alguns estudos tem indicado que vacas em lactação, em pastagens bem manejadas, não respondem a suplementação com fontes de proteína não degradável no rúmen (PNDR), indicando que o suprimento de energia tem sido o fator limitante para vacas de alta produção a pasto (Reeves et al., 1996; Hongerholt \& Muller, 1999; McCormick et al., 2001). A utilização de soja integral tostada, contendo cerca de $18 \%$ de extrato etéreo e com cerca de 38 a $40 \%$ de $\mathrm{PB}$, sendo $50 \%$ desta não degradada no rúmen (Faldet \& Satter, 1991; Faldet et al., 1991) pode ser uma forma de incrementar a densidade energética e o suprimento de PNDR.

O objetivo deste trabalho foi avaliar o efeito da inclusão de soja integral tostada no concentrado suplementar de vacas da raça Holandesa em pastagem de coastcross.

\section{Material e Métodos}

O experimento foi realizado na Embrapa - Centro Nacional de Pesquisa de Gado de Leite (CNPGL), no Campo Experimental de Coronel Pacheco, MG, $\left(21^{\circ} 33^{\prime} 22^{\prime \prime}\right.$ de latitude $\mathrm{S}$ e $43^{\circ} 6^{\prime} 15^{\prime \prime}$ de longitude $\left.\mathrm{O}\right)$. O clima é do tipo Cwa (mesotérmico), com verões chuvosos e invernos secos, com precipitação média anual de $1.500 \mathrm{~mm}$, distribuídos de forma irregular. $\mathrm{O}$ trabalho teve início em 16 de dezembro de 1997 e terminou em 25 de março de 1998.

Foram comparados dois tipos de concentrados (Tabela 1) fornecidos para vacas da raça Holandesa, mantidas em pastagem de coastcross: A) concentrado padrão, que já vinha sendo fornecido ao rebanho de vacas da raça Holandesa da Embrapa (CNPGL), com $23,5 \%$ de PB (15,3\% de PDR na MS) e $80 \%$ de NDT e B) concentrado contendo soja integral tostada, com $19,5 \%$ de PB, 9,3\% PDR $86 \%$ de NDT, na base da matéria seca.

Foram utilizadas 18 vacas da raça Holandesa (nove por tratamento), de segunda à quarta lactação, pesando em média 490,6 kg de peso vivo, com cerca

R. Bras. Zootec., v.32, n.5, p.1243-1249, 2003 
Tabela 1 - Ingredientes e composição percentual dos concentrados experimentais utilizados pelas vacas em lactação em pastagem de coast-cross, no terço inicial da lactação

Table 1 - Ingredients and percentual composition of experimental concentrate feeds utilized by lactating cows grazing coast-cross pasture, during the initial 100 days of lactation

\begin{tabular}{|c|c|c|}
\hline & $\begin{array}{l}\text { Concentrado } \\
\text { Concentrate }\end{array}$ & $\begin{array}{l}\text { Concentrado com soja integral tostada } \\
\text { Toated whole soybean-enriched concentrate }\end{array}$ \\
\hline \multicolumn{3}{|l|}{ Ingredientes (\%) } \\
\hline $\begin{array}{l}\text { Fubá de milho } \\
\text { Ground corn }\end{array}$ & 48 & 62 \\
\hline $\begin{array}{l}\text { Farelo de soja } \\
\text { Soybean meal }\end{array}$ & 35 & - \\
\hline $\begin{array}{l}\text { Soja integral tostada (SIT) } \\
\text { Roasted whole soybean (SIT) }\end{array}$ & - & 35 \\
\hline $\begin{array}{l}\text { Farelo de trigo } \\
\text { Wheat bran }\end{array}$ & 14 & - \\
\hline $\begin{array}{l}\text { Mistura mineral } \\
\text { Mineral mixture }\end{array}$ & 1 & 1 \\
\hline $\begin{array}{l}\text { Calcário calcítico } \\
\text { Calcitic lime }\end{array}$ & 1 & 1 \\
\hline $\begin{array}{l}\text { Bicarbonato de sódio } \\
\text { Sodium bicarbonate }\end{array}$ & 1 & 1 \\
\hline $\begin{array}{l}\text { Nutrientes (\% na MS) } \\
\text { Nutrients }(\% \text { of } D M)\end{array}$ & & \\
\hline $\begin{array}{l}\text { Proteína bruta } \\
\text { Crude protein }(C P)\end{array}$ & 23,5 & 19,5 \\
\hline $\begin{array}{l}\text { Proteína degradável no rúmem (PDR) } \\
\text { Rumen degradable protein ( } R D P)\end{array}$ & 15,3 & 9,3 \\
\hline $\begin{array}{l}\text { Nutrientes digestíveis totais (NDT) } \\
\text { Total digestible nutrients (TDN) }\end{array}$ & 80,0 & 86,0 \\
\hline
\end{tabular}

de 15 a 30 dias pós-parto e com potencial de produção entre 5.000 e $6.000 \mathrm{~kg} /$ lactação. As vacas foram distribuídas nos dois tratamentos experimentais, de acordo com a ordem de lactação e época do parto, em três repetições de área (três vacas por repetição), para as estimativas de produção de leite por área e taxas de lotação. Para produção de leite/vaca/dia, a vaca foi considerada a unidade experimental.

A pastagem de coastcross foi estabelecida em área de várzea, em 1992, em solo classificado como Aluvial Eutrófico, conforme Vilela et al. (1996). Desde o estabelecimento, a pastagem de coastcross foi usada para outras avaliações de produção de leite de vacas da raça Holandesa sob pastejo, com adubações anuais de $350 \mathrm{~kg} / \mathrm{ha}$ de N, $80 \mathrm{~kg} / \mathrm{ha}$ de $\mathrm{P}_{2} \mathrm{O}_{5}$ e $280 \mathrm{~kg} / \mathrm{ha}$ de $\mathrm{K}_{2} \mathrm{O}$, fracionada em dez aplicações em cobertura.

No presente estudo, a pastagem de coastcross foi dividida em três áreas semelhantes e estas subdivididas, com cercas eletrificadas, em 26 piquetes com $305 \mathrm{~m}^{2}$ cada um. Foi adotado o pastejo rotativo com o período de ocupação do piquete sendo de um dia e o de descanso de 25 dias. Durante o período experimental (16/12/1997 a 25/03/1998), a adubação correspondeu a aplicação de 140, 32 e $112 \mathrm{~kg} / \mathrm{ha}$ de $\mathrm{N}, \mathrm{P}_{2} \mathrm{O}_{5}$ e $\mathrm{K}_{2} \mathrm{O}$, respectivamente.

Durante a condução do experimento, foram estimadas, semanalmente, na véspera e imediatamente após o pastejo, as quantidades de forragem disponível e residual da pastagem. Essa estimativa se baseou na quantidade de forragem cortada, antes (forragem disponível) e após (forragem residual) o pastejo, a 8 $\mathrm{cm}$ acima do nível do solo, e retirada do interior de um quadrado de um metro de lado, lançado ao acaso por três vezes em cada piquete. Toda vegetação existente abaixo do extrato de $8 \mathrm{~cm}$ foi desconsiderada. Parte da forragem colhida antes de cada pastejo foi levada ao laboratório para se estimar a qualidade da forragem disponível, com base nos teores de proteína bruta e de digestibilidade "in vitro" da matéria seca. $\mathrm{Na}$ média dos 100 dias do período experimental, quando os animais entravam em cada piquete, a disponibilidade de forragem da pastagem estava próxima de $5.500 \mathrm{~kg} /$ ha de matéria seca, enquanto a quantidade de forragem residual existente no momento de saída dos animais do piquete era ao redor de $3.000 \mathrm{~kg} / \mathrm{ha}$ de matéria seca. Os piquetes eram 
providos de água e sombra natural.

As vacas eram ordenhadas duas vezes ao dia, às 7 e $16 \mathrm{~h}$, ocasião em que os dois grupos receberam em cada ordenha $4,5 \mathrm{~kg} / \mathrm{vaca}$ de concentrado.

Os dados foram analisados conforme casualização inicial em blocos, com parcelas subdivididas, com os concentrados experimentais alocados nas parcelas, e nas subparcelas, os pesos a cada duas semanas ou as médias semanais de produção leiteira. As produções de leite iniciais foram utilizadas como covariável para análise e ajustes das médias. Para os dados referentes à pastagem, taxas de lotação e produção por área, foram consideradas três repetições de área, cada uma com três vacas (nove por tratamento). As produções médias de leite, por repetição de área, após devidamente ajustadas pelos quadrados mínimos, tomando as produções iniciais das vacas como covariável, foram usadas para a análise de variância da produção diária de leite por hectare, corrigido para 3,5\% de gordura. A casualização em função da ordem de lactação e época de parto levou à discrepância entre as médias de peso vivo dos animais dos dois tratamentos experimentais. Dessa forma, o peso vivo dos animais, ao início do experimento foi usado como covariável, na análise da produção de leite. Para produção de leite por vaca por dia, a vaca (nove por tratamento) foi considerada a unidade experimental.

\section{Resultados e Discussão}

O experimento foi conduzido no período das chuvas e de elevada temperatura, época de pleno

desenvolvimento vegetativo das gramíneas forrageiras tropicais, o que permitiu manter na pastagem de coastcross a elevada taxa de lotação, ou seja 6,2 vacas/ha. A forragem disponível apresentou qualidade nutricional relativamente adequada para produção de leite a pasto, com média de $12,1 \%$ de PB e 57,0\% de DIVMS (Figura 1).

A produção média de leite aumentou $(\mathrm{P}<0,04)$ de $19,8 \mathrm{~kg} / \mathrm{vaca} /$ dia para $22,2 \mathrm{~kg} / \mathrm{vaca} /$ dia para as vacas que receberam concentrado contendo soja integral tostada (Tabela 2). Os valores correspondentes para as produções corrigidas para 3,5\% de gordura foram 19,7 e $23,6 \mathrm{~kg} / \mathrm{vaca} / \mathrm{dia}(\mathrm{P}<0,03)$, respectivamente, uma vez que o teor de gordura do leite foi de $4,16 \%(\mathrm{P}<0,06)$ para as vacas que receberam concentrado com soja integral tostada, contra 3,49\% do grupo testemunha.

A magnitude da resposta à inclusão da soja integral tostada no concentrado foi semelhante ao incremento de $3,2 \mathrm{~kg} / \mathrm{vaca} /$ dia de leite corrigido para 3,5\% de gordura, observado na pesquisa realizada na Embrapa Gado de Leite em resposta a inclusão de $700 \mathrm{~g} / \mathrm{vaca} / \mathrm{dia}$ de fonte comercial de gordura insolúvel no rúmen (Vilela et al., 2002).

Tabela 2 - Produção e composição do leite e variação do peso vivo de vacas recebendo concentrado contendo soja integral tostada, no terço inicial da lactação e a taxa de lotação da pastagem de coast-cross

Table 2 - Milk production and composition and live weight variation of cows fed roasted whole soybean-enriched concentrate during the initial 100 days of lactation and the stocking rate of coast-cross pasture

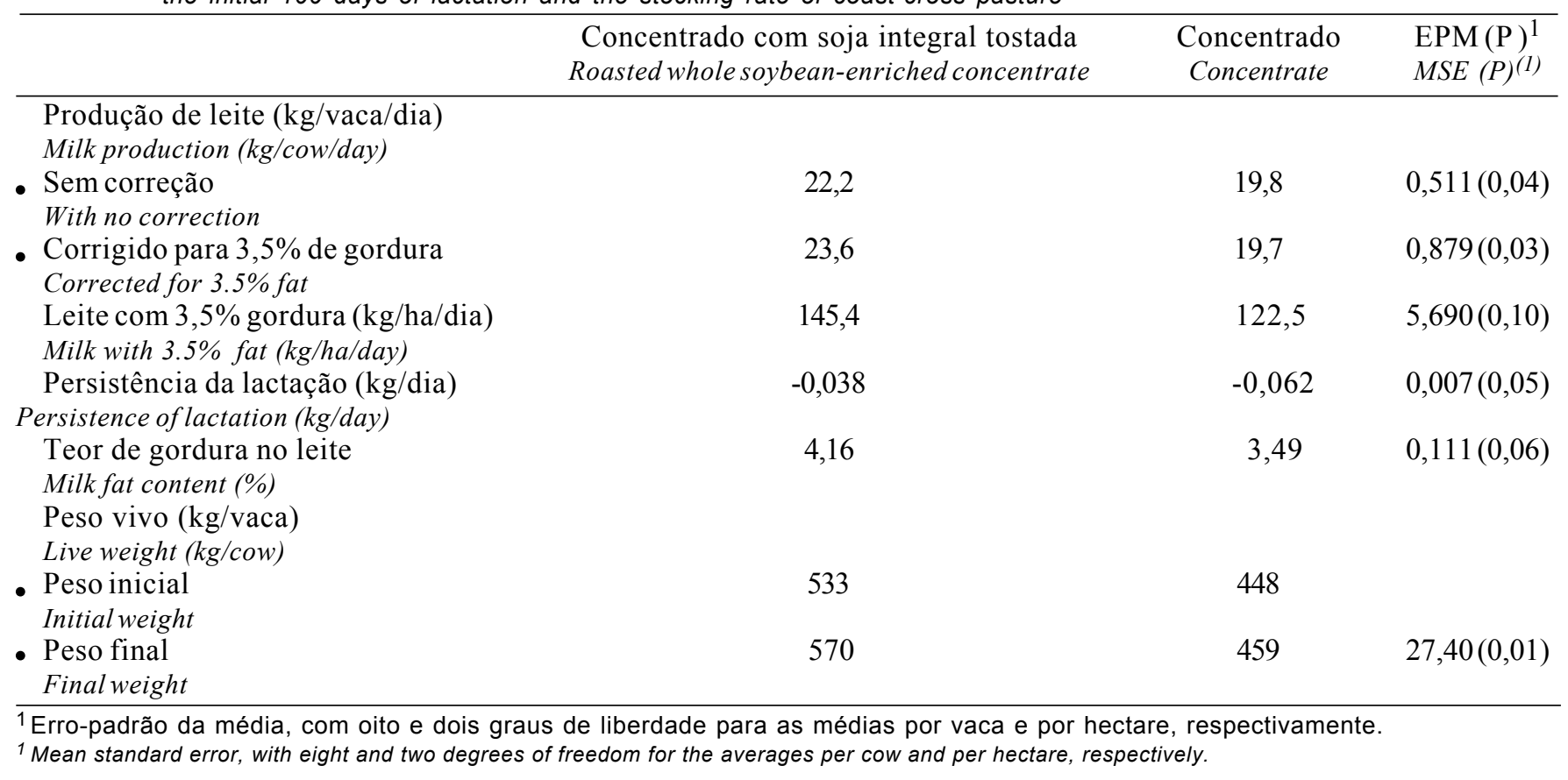

R. Bras. Zootec., v.32, n.5, p.1243-1249, 2003 


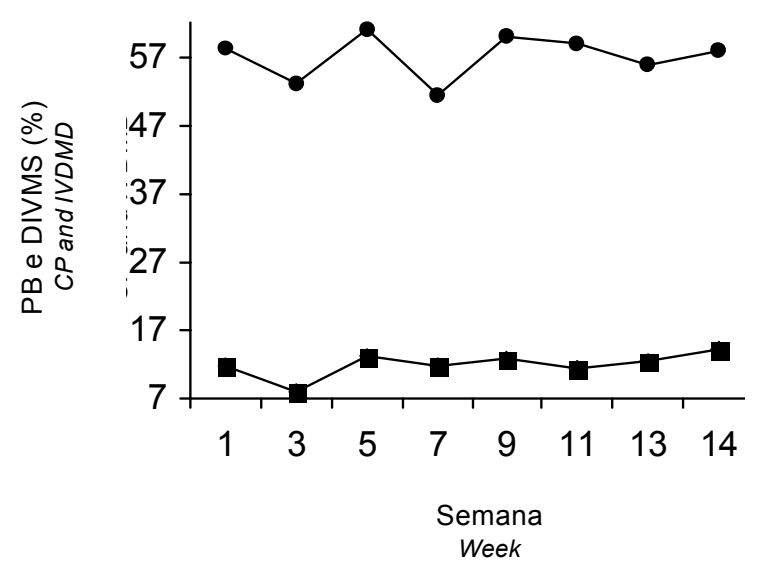

Figura 1 - Teores de proteína bruta (ם) e digestibilidade in vitro da matéria seca (•) de amostras do pasto de coastcross, coletadas por pastejo simulado.

Figure 1 - Crude protein ( $\mathbf{\square})$ and in vitro dry matter digestibility (•) levels of samples from coastcross pasture, collected by simulated grazing technique.

Vários trabalhos têm mostrado aumentos na produção de leite ou de leite corrigido para teor padrão de gordura, com o uso de soja integral tostada quando comparada com soja integral crua ou farelo de soja (Grummer et al., 1994; Knapp et al., 1991; Tice et al., 1993). Tice et al. (1993) constataram que o desaparecimento dos compostos nitrogenados no intestino tendeu a ser maior, em porcentagem do fluxo duodenal, para vacas que receberam soja integral tostada do que para vacas que receberam soja crua. Além disso, verificaram que a tostagem da soja integral decresceu o teor de $\mathrm{N}$ amoniacal no rúmen, aumentou o teor de PNDR e aumentou a produção de leite. Tice et al. (1994) também verificaram que a tostagem da soja integral aumentou a digestibilidade dos ácidos graxos no trato intestinal de vacas em lactação e o uso da soja integral tostada tendeu a aumentar o teor de ácidos graxos polissaturados da gordura do leite, em relação aos animais que receberam soja integral crua.

No presente estudo, os teores de gordura do leite, inicialmente baixos para ambos os tratamentos, aumentou, no decorrer do experimento, com a inclusão de soja integral tostada, permanecendo baixos para o grupo testemunha (Figura 2). Os teores de gordura mais elevados foram, provavelmente, devido ao efeito da tostagem, como o reportado por Tice et al. (1994), que melhora a digestibilidade dos ácidos graxos e também pelo aumento no teor de ácidos graxos polissaturados, principalmente pela maior concentração de C18:2. Chouinard et al. (2001) constataram que a tostagem aumentou as concentrações do isômero, o ácido linoléico conjugado (ALC ou CLA), que tem sido, ultimamente, objeto de muitos estudos, pelo seus efeitos benéficos à saúde, principalmente pelos seus efeitos anticarcinogênicos (Kelly \& Bauman, 1996).

A maior produção de leite por área $(\mathrm{P}<0,10)$ de $22,9 \mathrm{~kg} / \mathrm{ha} / \mathrm{dia}$ (intervalo de confiança da diferença, com $95 \%$ de probabilidade foi de $-11,7$ a $57,5 \mathrm{~kg} / \mathrm{ha} /$ dia) foi proporcionada pelo grupo de vacas que recebeu concentrado contendo soja integral tostada. Essa produção poderia ter sido mais elevada, se não fossem as diferenças $(\mathrm{P}<0,01)$ em peso vivo entre as vacas dos dois grupos. Essa diferença por vaca foi próxima de $100 \mathrm{~kg}$, favorável às que receberam concentrado com soja integral tostada, e manteve-se constante durante o período experimental (Figura 3). Como a taxa de lotação média da pastagem durante os 100 dias de execução do experimento foi fixa e mantida em 6,2 vacas/ha, a pastagem das vacas que recebeu soja integral tostada foi submetida à maior pressão de pastejo. Essa diferença na pressão de pastejo, que corresponde a $600 \mathrm{~kg} / \mathrm{ha}$ a mais de peso vivo, pode ter impedido maior produção de leite.

Apesar de produzirem mais leite, vacas de maior peso vivo tem maiores custos nutricionais para mantença (Visscher et al, 1994; Veerkamp, 1998), principalmente se mantidas a pasto, com custos energéticos para locomoção em ambientes com tem-

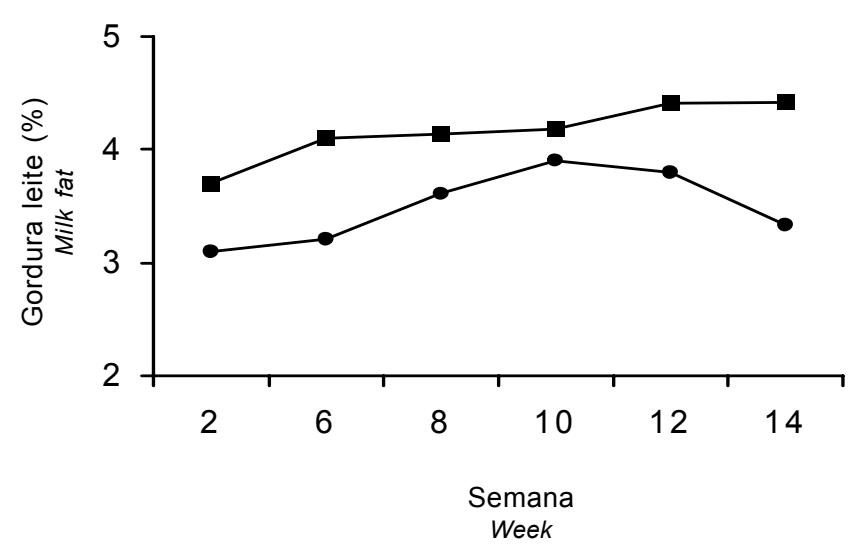

Figura 2 - Teores de gordura do leite de vacas em pastagem de coastcross, durante o período experimental, em função da composição do concentrado suplementar, contendo soja integral tostada (ם) ou não (testemunha, $\bullet$ ).

Figure 2 - Milk fat content of cows grazing coast-cross pasture, during the experimental period, according to the supplement concentrate composition, as containing roasted whole soybean (ם) or not (control, $\bullet$ ) 
peratura e umidade elevadas (Visscher et al., 1994). Se por um lado os custos nutricionais são maiores, por outro, vacas mais pesadas potencialmente produzem mais leite, conforme foi constatado no presente trabalho. Ao se utilizar o peso vivo no início do experimento, como covariável, numa avaliação da produção de leite corrigida para $3,5 \%$ de gordura, as médias ajustadas pela covariável peso vivo inicial, mostraram-se semelhantes $(\mathrm{P}>0,55)$, sendo as médias ajustadas de 20,1 e 21,7 kg/vaca/dia, em relação aos tratamentos que consistiram de fornecer aos animais concentrado com e sem (testemunha) soja integral tostada, respectivamente. Assim, a diferença na produção de leite observada nos dois tratamentos deve ser atribuída à diferença de peso das vacas de cada tratamento, no início do experimento. As vacas de ambos os tratamentos ganharam peso ao longo do ensaio, não sendo esperado que parte essa produção de leite, tenha ocorrido por mobilização de reservas corporais das vacas.

O grupo de vacas que recebeu concentrado suplementar contendo soja integral tostada apresentou, em média, produção de leite de $145,4 \mathrm{~kg} / \mathrm{ha} / \mathrm{dia}$, corrigido para $3,5 \%$ de gordura (Tabela 2 ), o que ao

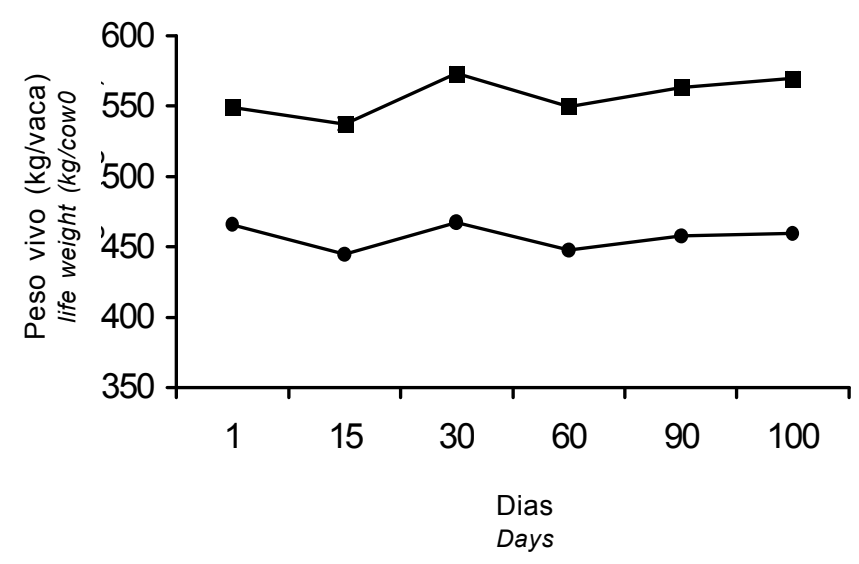

Figura 3 - Mudanças no peso vivo de vacas em pastagem de coast-cross durante o período experimental, em função da composição do concentrado, contendo soja integral tostada (ם) ou não (testemunha, $\bullet$ ).

Figure 3 - Live weight alterations in cows grazing coastcross pasture during the experimental period, according to concentrate composition, containing roasted whole soybean (घ) or not (control,

R. Bras. Zootec., v.32, n.5, p.1243-1249, 2003 longo dos 100 dias de condução do experimento perfaz um total de $14.540 \mathrm{~kg}$ de leite/ha, o que mostra o elevadíssimo potencial forrageiro dessa gramínea para produção de leite, quando devidamente manejada e com a alimentação suplementar adequada ao potencial genético das vacas em pastejo.

A utilização do concentrado suplementar com soja integral tostada permite manter a persistência da lactação $(\mathrm{P}<0,05)$ no seu terço inicial, com as vacas mostrando queda de $0,038 \mathrm{~kg}$ de leite/dia, o que daria uma queda de $3,8 \mathrm{~kg}$ de leite/vaca entre o início e o final do período experimental de 100 dias. Quanto às vacas do grupo testemunha, esses valores correspondem a $0,062 \mathrm{~kg} / \mathrm{dia}$ e $6,2 \mathrm{~kg} / \mathrm{vaca}$, respectivamente (Tabela 2).

\section{Conclusões}

O fornecimento de concentrado suplementar com soja integral tostada aumenta o teor de gordura do leite produzido.

Vacas que recebem alimentação concentrada suplementar com soja integral tostada mostram melhor persistência da lactação, no seu terço inicial.

Pastagem bem manejada de coastcross possibilita taxas de lotação ao redor de seis vacas/ha, no verão, proporcionando, nesta época, produção de leite por área elevada, ou seja, $14.000 \mathrm{~kg} / \mathrm{ha}$ nos 100 primeiros dias de lactação.

\section{Literatura Citada}

ALVIM, M.J.; VERNEQUE, R.S.; VILELA, D. et al.Estratégia de fornecimento de concentrado para vacas da raça Holandesa em pastagem de Coast-cross. Pesquisa Agropecuária Brasileira, v.34, n. 9, p.1711-1720, 1999.

ALVIM, M.J.; VILELA, D.; LOPES, R.S. Efeitos de dois níveis de concentrado sobre a produção de leite de vacas da raça Holandesa em pastagem de Coast-cross (Cynodon dactylon L. (Pers.). Revista da Sociedade Brasileira de Zootecnia, v.26, n.5, p.967-975, 1997.

ALVIM, M.J.; XAVIER, D.F.; BOTREL, M.A. et al. Resposta do "coast-cross" (Cynodon dactylon (L.) Pers.) a diferentes doses de nitrogênio e intervalos de cortes. Revista Brasileira de Zootecnia, v.27, n.5, p.829-836, 1998.

BRYANT, A.M. Dairying in New Zealand. In: INTERNACIONAL GRASSLAND CONGRESS, 17., 1993, Palmerston North. Proceedings... Palmerston North, 1993. p.1587-1588.

CHOUINARD, P.Y.; CORNEAU, L.; BUTLER, W.R. et al. Effect of dietary lipid source on conjugated linoleic acid concentrations in milk fat. Journal of Dairy Science, v.84, n.2, p.680-690. 2001.

COWAN, R.T. Milk production from grazing systems in northern Australia. In: SIMPÓSIO INTERNACIONAL O FUTURO DOS SISTEMAS DE PRODUÇÃO DE LEITE NO BRASIL, 
Juiz de Fora. Anais... Juiz de Fora: Embrapa Gado de Leite, 1995. p.41-54.

DAVISON, T.M.; MARSCHKE, R.J.; BROWN, G.W. Milk yields from feeding maize silage and meat-and-bone meal to Friesian cows grazing a tropical grass and legume pasture. Australian Journal Experimental Agriculture and Animal Husbandry, v.22, n.1, p.147-154, 1982.

ERZAGHI, P.; HERBEIN, J.H.; POLAN, C.E. Intake, site, and extent of nutrient digestion of lactating cows grazing pasture. Journal of Dairy Science, v.79, n.9, p.1581-1589, 1996.

FALDET, M.A.; SATTER, L.D. Feeding heat-treated full fat soybeans to cows in early lactation. Journal of Dairy Science, v.74, n.9, p.3047-3054. 1991.

FALDET, M.A.; VOSS, V.L.; BRODERICK, G.A. et al. Chemical, in vitro, and in situ evaluation of heat-treated soybean proteins. Journal of Dairy Science, v.74, n.8, p.25482554, 1991.

FONTANELI, R.S. Forage systems per year-round grazing by lactating dairy cows. Gainesville: University of Florida, 1999. 220p. Thesis (Doctor).

GRUMMER, R.R.; LUCK, M.L. ; BARMORE, J.A. Lactational performance of dairy cows fed raw soybeans, with or without animal by-product proteins, or roasted soybeans. Journal of Dairy Science, v.77, n.5, p.1354-1359, 1994.

HERRERA, R.S. La calidad de los pastos. In: INSTITUTO DE CIENCIA ANIMAL (Habana, Cuba). Los pastos en Cuba, Havana. T.2, 1983. p.59-115.

HONGERHOLT, D.D.; MULLER, L.D. Supplementation or rumen-undegradable protein to the diets of early lactation Holstein cows on grass pasture. Journal of Dairy Science, v.81, n.8, p.2204-2214, 1998.

KELLY, M.L.; BAUMAN, D.E. Conjugated linoleic acid: a potent anticarcinogenic found in milk fat. In: CORNELL NUTRITION CONFERENCE FOR FEED MANUFACTURERS, 58., 1996, Rochester. Proceedings... Rochester, 1996. p.217-226.

KNAPP, D.M.; GRUMMER, R.R.; DENTINE, M.R. The response of lactating dairy cows to increasing levels of whole roasted soybeans. Journal of Dairy Science, v.74, n.10, p.2563-2572, 1991.

McCORMICK, M.E.; WARD, J.D.; REDFEARN, D.D. et al. Supplemental dietary protein for grazing dairy cows: effect on pasture intake and lactational performance. Journal of Dairy Science, v.84, n.4, p.896-907, 2001.

NOCEK, J.E. Nutritional considerations for the transition cow. In: CORNELL NUTRITION CONFERENCE FOR FEED MANUFACTURERS, 57., 1995, Rochester. Proceendings... Rochester, 1995. p.121-137.

NATIONAL RESEARCH COUNCIL - NRC. Nutrient requirements of dairy cattle. 7.ed. Washington, D.C.: National Academy Press, 2001. 381p.
REEVES, M.; FULKERSON, W.J.; KELLAWAY, R.C. Production responses of dairy cows grazing well-managed kikuyu pastures to energy and protein supplementation. Australian Journal of Experimental Agriculture, v.36, n.3, p. 763-770, 1996.

STOBBS, T.H. Milk production per cow and per hectare from tropical pastures. (milk production from tropical pastures). In: SEMINARIO INTERNATIONAL DE GANADERIA TROPICAL PRODUCTION DE FORRAJES, 1976, Mexico. Memoria... Ciudad del Mexico: Secretaria de Agricultura e Ganaderia/Banco del Mexico S.A., 1976. p.129-146.

TICE, E.M.; EASTRIDGE, M.L.; FIRKINS, J.L. Raw soybeans and roasted soybeans of different particle sizes. 1. Digestibility and utilization by lactating cows. Journal of Dairy Science, v.76, n.1, p.224-235, 1993.

TICE, E.M.; EASTRIDGE, M.L.; FIRKINS, J.L. Raw soybeans and roasted soybeans of different particle sizes. 2. Fatty acid utilization by lactating cows. Journal of Dairy Science, v.77, n.1, p. 166-180, 1994.

Van SOEST, PJ. Nutritional ecology of the ruminant. 2.ed. Ithaca: Cornell University Press, 1994.

VEERKAMP, R.F. Selection for economic efficiency of dairy cattle using information on live weight and feed intake: a review. Journal of Dairy Science, v.81, n.4, p.1109-1119, 1998.

VILELA, D.; ALVIM, M.J.; CAMPOS, O.F.; RESENDE, J.C. Produção de leite de vacas holandesas em confinamento ou em pastagem de coast-cross. Revista Sociedade Brasileira de Zootecnia, v.25, n.5, p.1228-1244, 1996.

VILELA, D.; ALVIM, M.J.; MATOS, L.L.; MATIOLLI, J.B. Utilização de gordura protegida durante o terço inicial da lactação de vacas leiteiras, em pastagem de coast-cros. Pesquisa Agropecuária Brasileira, v.37, n.10, p.15031509, 2002.

VISSCHER, P.M.; BOWMAN, PJ.; GODDARD, M.E. Breeding objectives for pasture based dairy production systems. Livestock Production Science, v.40, p.123-137, 1994.

Recebido em: 11/07/02

Aceito em: 09/01/03 